\title{
Zika virus infection and Guillain-Barré syndrome: a review focused on clinical and electrophysiological subtypes
}

\author{
Antonino Uncini, ${ }^{1}$ Nortina Shahrizaila, ${ }^{2}$ Satoshi Kuwabara ${ }^{3}$
}

'Department of Neuroscience, Imaging and Clinical Sciences, University 'G. d'Annunzio' Chieti-Pescara, Chieti, Italy 2Faculty of Medicine, University of Malaya, Kuala Lumpur, Malaysia

${ }^{3}$ Department of Neurology, Graduate School of Medicine, Chiba University, Chiba, Japan

\section{Correspondence to} Professor Antonino Uncini, Department of Neuroscience, Imaging and Clinical Sciences, University 'G. d'Annunzio', Via Luigi Polacchi, Chieti 66100, Italy; uncini@unich.it

Received 19 July 2016 Accepted 14 October 2016 Published Online First: 31 October 2016

\section{CrossMark}

To cite: Uncini $A$, Shahrizaila N, Kuwabara S. $J$ Neurol Neurosurg Psychiatry 2017:88:266-271.

\section{ABSTRACT}

In 2016, we have seen a rapid emergence of Zika virusassociated Guillain-Barré syndrome (GBS) since its first description in a French-Polynesian patient in 2014. Current evidence estimates the incidence of GBS at 24 cases per 100000 persons infected by Zika virus. This will result in a sharp rise in the number of GBS cases worldwide with the anticipated global spread of Zika virus. A better understanding of the pathogenesis of Zika-associated GBS is crucial to prepare us for the current epidemic. In this review, we evaluate the existing literature on GBS in association with Zika and other flavivirus to better define its clinical subtypes and electrophysiological characteristics, demonstrating a demyelinating subtype of GBS in most cases. We also recommend measures that will help reduce the gaps in knowledge that currently exist.

\section{INTRODUCTION}

Since the near elimination of poliomyelitis, Guillain-Barré syndrome (GBS) has become the most frequent cause of acute flaccid paralysis worldwide. The presence of antecedent infection up to 4 weeks prior to the onset of neurological symptoms makes GBS the prototype of postinfectious autoimmune diseases. ${ }^{1}$ The last 8 months have seen an increase in reports of GBS in association with Zika virus, an arthropod-borne flavivirus. ${ }^{2}$ There is real concern that the Zika virus outbreak currently concentrated in Latin America and the Pacific Islands will spread leading to a global epidemic. The incidence of Zika-associated GBS is estimated at 0.24 per 1000 infections. ${ }^{3} \mathrm{~A}$ recent analysis from seven countries (Brazil, Colombia, the Dominican Republic, El Salvador, Honduras, Suriname and Venezuela) reported an increase in the incidence of Zika-associated GBS that is 2.0-9.8 times higher than the pre-Zika era. ${ }^{4}$ Although still a rare complication in the context of an emerging epidemic or pandemic, the marked increase in GBS cases worldwide could overwhelm hospital and intensive care resources of even the best equipped of healthcare systems.

There is an urgent need for health professionals to be confident at recognising the clinical features of GBS and accurately interpreting the clinical investigations. Nerve electrophysiology studies play a crucial role in the diagnosis of GBS by confirming the presence of neuropathy. Importantly, as the pathogenesis of Zika-associated GBS is unknown, electrophysiology when carefully interpreted may provide insights by determining which components of the peripheral nerve, myelin or axon, are primary targets.

In this review, current knowledge of the clinical characteristics of Zika-associated GBS is described, with emphasis placed on the electrophysiological findings. Existing literature on GBS associated with other flavivirus is also reviewed to lend supportive evidence as to the possible pathophysiology of GBS in association with Zika virus.

\section{METHODS}

\section{Search strategy}

We performed a PubMed search to identify studies reporting GBS in association with Zika and other flavivirus. We searched databases until 7 October 2016 using the following terms: (1) GBS terms: 'Guillain-Barre syndrome' and 'flaccid paralysis', and (2) flavivirus terms: 'flavivirus', 'Zika virus', 'Zika infection', 'dengue fever', 'dengue', 'dengue virus', 'West Nile virus', 'Japanese encephalitis virus', 'yellow fever virus', 'St Louis encephalitis virus', 'Murray Valley encephalitis virus' and 'tickborne encephalitis virus'. We included references of the relevant articles as part of our search.

\section{Clinical features of Zika-associated GBS}

In 2014, the first description of GBS in association with Zika virus emerged in a case report of a female patient developing GBS during the 2013/ 2014 French-Polynesian Zika virus outbreak. ${ }^{5}$ The initial presentation was distal limb paraesthesia rapidly progressing over a period of 2 days resulting in areflexic tetraparesis. Other clinical features include bilateral facial palsy and autonomic dysfunction with sustained ventricular arrythmia and orthostatic hypotension. Cerebrospinal fluid (CSF) analysis showed albumin-cytological dissociation and electrophysiology demonstrated demyelinating polyneuropathy. Treatment with intravenous immunoglobulin was administered and the patient made good recovery, ambulating independently at day 40 of disease onset. In keeping with a diagnosis of GBS, a history of antecedent influenza-like illness was elicited 7 days prior to the onset of neurological symptoms. At the time, the patient had fever, myalgia, cutaneous rash and conjunctivitis. Subsequent infective serological analyses would support a recent infection with Zika and possibly dengue infections.

Since then, there have been several case reports and case series of Zika-associated GBS (table 1). ${ }^{3}$ 6-15 
The largest series to date have been reported from the French-Polynesian outbreak with 42 patients and from Colombia with 68 patients. ${ }^{3} 812$ The diagnosis of GBS in both case series was made based on the Brighton Collaboration criteria, ${ }^{16}$ although in the French-Polynesian study, the level of diagnostic certainty for their cases was not reported. The key clinical features of GBS include rapid progression to nadir (median of 6 days), short plateau phase (median of 4 days), classical GBS presentation with symmetrical limb weakness (74\%, non-ambulating in $44 \%$ ) but with a high proportion of facial palsy (64\% at presentation, $79 \%$ at nadir with $60 \%$ bilateral). In $29 \%$ of cases, there was respiratory compromise necessitating ventilatory support. A history of antecedent viral illness was reported at a median of 6 days prior to the onset of neurological symptoms. Most patients (93\%) had raised CSF protein. The overall outcome reported no deaths and 57\% ambulating independently by 3 months of disease onset. The speed of recovery appears to be similar to that of GBS in general; $~ 75 \%$ of GBS patients regain the ability to walk unaided at 6 months after onset. $^{17}$

In the Colombian study, the authors report 56 (82\%) patients fulfilling level 1 or 2 of the Brighton diagnostic criteria based on CSF analysis, neurophysiology or both, whereas 6 patients fulfilled criteria level 3. ${ }^{12}$ Six patients had GBS variants: four Miller Fisher syndrome, one facial diplegia with areflexia and one sensory GBS. The clinical features were similar to that reported in the French-Polynesian study with presenting features of ascending paralysis (82\%) and in $50 \%$ of cases bilateral facial palsy. Mechanical ventilation was required in $31 \%$ of patients and autonomic dysfunction was present in $31 \%$ of cases. The long-term outcome was not reported, but there were three deaths as a result of respiratory failure and sepsis. Similar to the French-Polynesian study, there was a short median period of antecedent illness (7 days). Interestingly, 20 patients developed neurological symptoms during or immediately after the Zika infection, suggesting a parainfectious rather than postinfectious pattern that is typically seen in GBS. A similar presentation was also reported in a case of a patient developing Zika-associated GBS on returning from a trip to Tonga. ${ }^{14}$ The authors raised the possibility of a direct viral neuropathogenic mechanism or a hyperacute immune response in such cases rather than molecular mimicry that has been described in postinfectious GBS. However, the evidence in support for a direct neurotropism in Zika-associated GBS is currently lacking.

Other case reports of Zika-associated GBS have described similar clinical features, including the occasional reports of GBS variants. In one report from Brazil, the authors described a patient with symmetrical weakness of both lower limbs associated with absent reflexes and reduced sensation. ${ }^{9}$ The rest of the neurological examination, including the cranial nerves and upper limbs, were normal. The clinical presentation was in keeping with the paraparetic variant of GBS. In a case from Haiti, the authors reported a man presenting with acute facial diplegia associated with limb dysaesthesia, areflexia and mild ataxia. ${ }^{7}$ An initial diagnosis of the GBS variant, facial diplegia with paraesthesia, was made. Subsequently, the patient progressed to develop complete ophthalmoplegia and worsening ataxia, which would be more in keeping with the Miller Fisher syndrome spectrum of GBS, although IgG against GQ1b was negative.

As further reports of GBS associated with Zika virus emerge, it is important to recognise that there is heterogeneity in the clinical presentation and precision in the clinical descriptions of individual cases is key to the accurate clinical classification of GBS. ${ }^{18}$
Electrophysiology of Zika-associated GBS

Existing reports of the electrophysiological findings in Zika-associated GBS have provided conflicting results. Single case reports have suggested demyelinating neuropathy, ${ }^{5}$ 6 13-15 and the recent large series reported from Colombia have also demonstrated acute inflammatory demyelinating polyradiculoneuropathy (AIDP) in the majority of patients (78\%) (table 1). ${ }^{12}$ In contrast, findings from the French-Polynesian studies ${ }^{3}$ and a smaller series from Cucuta, Colombia, ${ }^{10}$ have argued for an axonal neuropathy. Electrophysiology plays an important part not only in supporting the diagnosis of GBS but also in the electrodiagnostic classification of its subtypes and in understanding the pathophysiology. In reaching an accurate electrodiagnosis of GBS, certain common pitfalls need to be overcome. ${ }^{19}$ There is increasing evidence to suggest that a single electrophysiology study performed at the initial stages of disease may not be reliable in defining the subtype when the current electrodiagnostic criteria are applied. ${ }^{20}$

In the reports from the French Polynesia, the authors performed electrophysiology on 37 patients at the first week of disease onset and at 4 months, reporting only the median values of the group. ${ }^{38}$ In the first week of disease onset, nerve conduction studies demonstrated mean prolonged distal motor latencies (DMLs) and reduced distal compound muscle action potential (CMAP) amplitudes. No conduction block or substantial mean conduction slowing in the intermediate nerve segments was reported (although the lowest conduction velocities ranged from $24.7 \mathrm{~m} / \mathrm{s}$ in the peroneal nerve to $29.9 \mathrm{~m} / \mathrm{s}$ in the median). ${ }^{38}$ The mean percentage increase in DMLs from upper limits of normal (ULN) was remarkable: median nerve 335\%, ulnar 202\% and peroneal 203\%. These strikingly prolonged DMLs far exceeds even the most conservative of cut-offs for demyelination $(150 \%$ of ULN) in the current electrodiagnostic criteria for inflammatory neuropathies. ${ }^{21}$ The mean distal CMAP duration in the first week of disease onset was also increased (peroneal nerve $128 \%$, median nerve $155 \%$ ), with individual values up to $320 \%$ of ULN. ${ }^{8}$ These values are more in keeping with those reported in AIDP and chronic inflammatory demyelinating polyradiculoneuropathy. ${ }^{22}{ }^{23}$ Repeat studies at 4 months in 19 patients showed improvement in DMLs and CMAP amplitudes. The authors concluded, based on these latter findings, that the diagnosis was consistent with acute motor axonal neuropathy (AMAN) with reversible conduction failure (RCF). However, the mean DMLs remained substantially prolonged at 4 months: median nerve $193 \%$, ulnar $146 \%$ and peroneal $120 \%$ of ULN, which would be atypical for AMAN with RCF. ${ }^{19}$

We first described that AMAN, besides axonal degeneration, is characterised by a transient conduction block and conduction slowing with typical associations to IgG antibodies against GM1 and GD1a (figure $1 \mathrm{~A}-\mathrm{C}$ ). ${ }^{24}$ At first examination, conduction block and slowing can mimic demyelination, but these rapidly resolve on serial studies performed within a few weeks. In the absence of abnormal temporal dispersion, these findings were referred to as RCF to distinguish them from classical demyelinating features. ${ }^{19} 24$ The concept of AMAN with RCF is supported by evidence from human pathological studies and animal models which indicates that AMAN is characterised by antibody-mediated and complement-mediated dysfunction/disruption due to microstructural changes in the axolemma at the nodes of Ranvier, termed 'nodopathy'. ${ }^{25}$ This results in a pathophysiological continuum in AMAN from transient nerve conduction failure to axonal degeneration. ${ }^{25}$ Although the cut-off criteria for RCF have not yet been precisely defined, our own unpublished analyses of patients with AMAN with RCF 
Table 1 Clinical and electrodiagnostic features of patients with Guillain-Barré syndrome associated with Zika virus and other flavivirus infection

\begin{tabular}{|c|c|c|c|c|}
\hline Report (year) & Country & $\begin{array}{l}\text { Number of } \\
\text { patients }\end{array}$ & Clinical features & Electrodiagnosis and findings \\
\hline \multicolumn{5}{|l|}{ Zika virus } \\
\hline Oehler et al (2014) $)^{5}$ & French-Polynesia & 1 & Classical GBS with facial palsy & AIDP: prolonged distal motor latency, delayed F waves, conduction block \\
\hline $\begin{array}{l}\text { Cao-Lormeau et al (2016) } \\
\text { Watrin et al }(2016)^{8}\end{array}$ & French-Polynesia & 42 & $\begin{array}{l}\text { Classical GBS }(79 \% \text { facial palsy at } \\
\text { nadir) }\end{array}$ & $\begin{array}{l}37 \text { patients reported as AMAN with RCF but had very prolonged mean distal motor latencies in median (12.4 ms), ulnar } \\
(5.8 \mathrm{~ms}) \text { and peroneal }(9.9 \mathrm{~ms}) \text { nerves, typically seen in AIDP }\end{array}$ \\
\hline Rozé et al (2016) $)^{13}$ & Martinique & 2 & Classical GBS with facial palsy & $\begin{array}{l}\text { AIDP: prolonged distal motor latency, slow velocities, temporal dispersion, conduction block, absent } \mathrm{F} \text { waves, } \\
\text { sural-sparing pattern. Needle electromyography normal }\end{array}$ \\
\hline Brasil et al (2016) ${ }^{9}$ & Brazil & 1 & Paraparetic GBS & Normal \\
\hline Fontes et al $(2016)^{6}$ & Brazil & 1 & $\begin{array}{l}\text { Lower limb weakness and facial } \\
\text { palsy }\end{array}$ & AIDP: no details but reported demyelinating pattern \\
\hline Siu et al $(2016)^{14}$ & $\begin{array}{l}\text { New Zealand/ } \\
\text { Tonga }\end{array}$ & 1 & Classical GBS & AIDP: prolonged distal motor latencies in median $(13.5 \mathrm{~ms})$, ulnar $(6.9 \mathrm{~ms})$, peroneal $(12.6 \mathrm{~ms})$, tibial $(9.8 \mathrm{~ms})$ \\
\hline Dirlikov et al (2016) ${ }^{11}$ & Puerto Rico & 34 & Classical GBS (63\% facial palsy) & 5 patients. No details but all reported as AIDP \\
\hline Arias et al $(2016)^{10}$ & Colombia & 19 & Classical GBS ( $42 \%$ facial palsy) & $\begin{array}{l}14 \text { patients. No details. } 10 \text { patients reported as AMAN but with prolonged distal motor latencies and sural-sparing } \\
\text { pattern. } 2 \text { patients inexcitable and } 2 \text { normal }\end{array}$ \\
\hline do Rosário et al (2016) ${ }^{15}$ & Brazil & 2 & Classical GBS with facial palsy & $\begin{array}{l}\text { AIDP. Case 1: prolonged distal motor latencies in ulnar }(6.2 \mathrm{~ms}) \text { and tibial }(7.7 \mathrm{~ms}) \text {; case 2: prolonged distal motor } \\
\text { latency in median }(7.5 \mathrm{~ms}) \text {, ulnar slowing }(30 \mathrm{~m} / \mathrm{s}) \text { and prolonged } \mathrm{F} \text { wave }(40 \mathrm{~ms})\end{array}$ \\
\hline Parra et al (2016) ${ }^{12}$ & Colombia & 68 & $\begin{array}{l}64 \text { classical GBS }(50 \% \text { bilateral facial } \\
\text { palsy) } \\
2 \text { Miller Fisher syndrome } \\
1 \text { facial diplegia with areflexia } \\
1 \text { pure sensory GBS }\end{array}$ & $\begin{array}{l}46 \text { patients. } 36 \text { AIDP with prolonged distal motor latencies, conduction block, and sural-sparing pattern; } 4 \text { equivocal; } \\
3 \text { inexcitable; } 2 \text { normal; } 1 \text { AMAN }\end{array}$ \\
\hline \multicolumn{5}{|l|}{ Dengue virus } \\
\hline Chew et al (1998) $)^{30}$ & Malaysia & 2 & Classical GBS with facial palsy & AIDP: prolonged distal latencies and reduced conduction velocity \\
\hline Esack et al (1999) $)^{31}$ & Trinidad & 1 & Classical GBS & AIDP: reported as predominantly demyelinating sensorimotor polyneuropathy \\
\hline Santos et al $(2004)^{32}$ & Brazil & 1 & Classical GBS with facial palsy & AIDP: no details but reported slowed motor conduction velocity \\
\hline Kumar et al $(2005)^{33}$ & India & 1 & Classical GBS & $\begin{array}{l}\text { AIDP: reduced motor and sensory amplitudes, normal distal latency and conduction velocity but prolonged F wave } \\
\text { latencies }\end{array}$ \\
\hline Chen and Lee $(2007)^{34}$ & Taiwan & 1 & Mild lower limb weakness & AIDP: prolonged distal latency, reduced amplitude, absent $\mathrm{H}$ and $\mathrm{F}$ waves \\
\hline Verma et al $(2011)^{35}$ & India & 3 & Details not provided & 2 AMSAN and 1 AIDP: no details reported \\
\hline Ralapanawa et al (2015) $)^{36}$ & Sri Lanka & 1 & Classical GBS with facial palsy & AIDP: no details but reported severe demyelination in upper and lower limbs \\
\hline Simon et al $(2016)^{37}$ & New Caledonia & 3 & $\begin{array}{l}\text { Classical GBS (facial palsy in } 2 \\
\text { patients) }\end{array}$ & $\begin{array}{l}\text { AIDP in } 2 \text { patients: slow conduction velocity, prolonged distal latency, delayed } \mathrm{F} \text { waves and presence of conduction } \\
\text { block. Normal conductions in } 1 \text { patient }\end{array}$ \\
\hline Boo et al $(2015)^{38}$ & Malaysia & 1 & $\begin{array}{l}\text { Mild distal lower limb weakness and } \\
\text { sensory impairment }\end{array}$ & AMAN: no details but reported axonal motor neuropathy \\
\hline \multicolumn{5}{|l|}{ Japanese encephalitis virus } \\
\hline Ravi et al $(1994)^{39}$ & India & 11 & Classical GBS & AIDP: no details but reported demyelination \\
\hline Xiang et al $(2014)^{40}$ & China & 1 & Classical GBS with facial palsy & AIDP: reported as acute demyelinating sensorimotor polyradiculoneuropathy \\
\hline \multicolumn{5}{|l|}{ West Nile virus } \\
\hline Ahmed et al $(2000)^{41}$ & USA & 1 & Classical GBS with facial palsy & AIDP: prolonged distal latencies, slow conduction velocities \\
\hline Sejvar et al $(2005)^{42}$ & USA & 4 & $\begin{array}{l}\text { Classical GBS (facial palsy in } 1 \\
\text { patient) }\end{array}$ & AIDP: no details but reported as predominantly demyelinating sensorimotor polyneuropathy \\
\hline
\end{tabular}




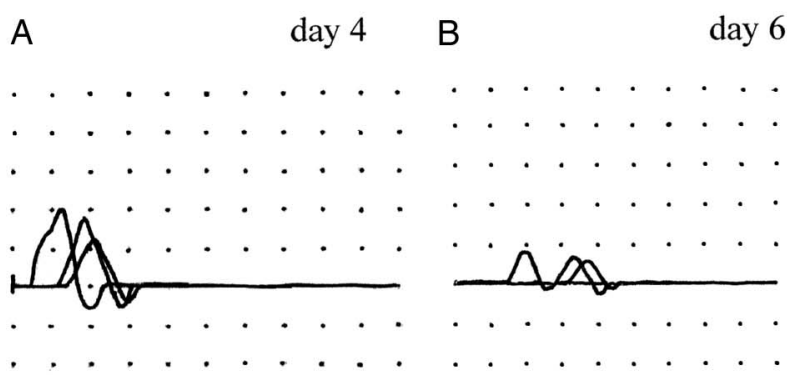

$$
\text { day } 11
$$

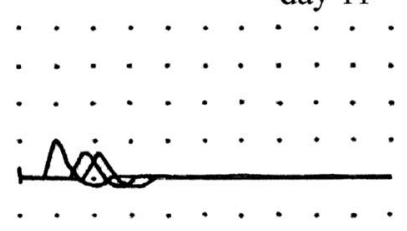

day 12

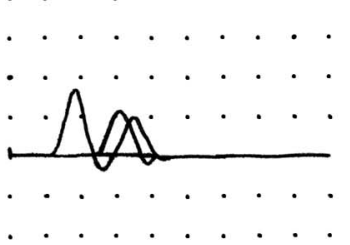

day 25
C

day 10

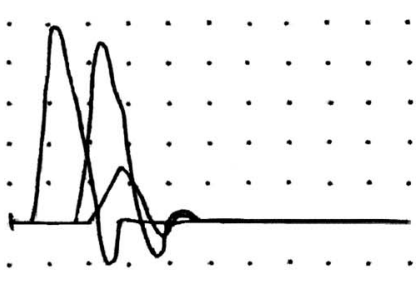

day 20

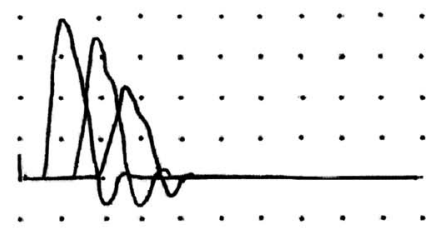

day 27
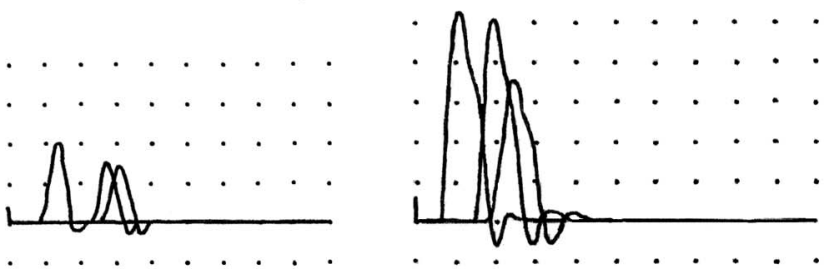

Figure 1 Electrophysiological patterns of acute motor axonal neuropathy (AMAN). Superimposed compound muscle action potentials (CMAPs) recorded from the abductor digiti minimi after ulnar nerve stimulation at the wrist, below-elbow and above-elbow and from the extensor digitorum brevis after stimulation at the ankle, below peroneal head and above peroneal head. Calibration is $5 \mathrm{~ms} / 2 \mathrm{mV}$ in all tracings. (A) AMAN with axonal degeneration in the ulnar nerve. Distal CMAP amplitude was already decreased $(4 \mathrm{mV})$ on day 4 with further decrement $(2 \mathrm{mV})$ on day 11 . The patient had IgG anti-GM1 and anti-GD1a. (B) AMAN with distal reversible conduction failure (RCF) in the peroneal nerve. On day 6, distal CMAP amplitudes were reduced $(1.6 \mathrm{mV})$ with increased distal motor latency $(7.4 \mathrm{~ms}, 132 \%$ of upper limit of normal). On day 25 , there was $250 \%$ increment of distal CMAP amplitude and distal motor latency was normal (4.8 ms) without the development of temporal dispersion of CMAP. The patient had IgG anti-GD1b. (C) AMAN with RCF in intermediate nerve segment of the ulnar nerve. On day 10, the CMAP amplitude ratio across the elbow was 0.3 . This ratio improved in the following recordings up to 0.7 on day 27 without the development of temporal dispersion of CMAPs. Conduction velocity across the elbow was slow $(38 \mathrm{~m} / \mathrm{s})$ on day 10 but improved in parallel with the resolution of conduction failure (48 $\mathrm{m} / \mathrm{s}$ on day 27). The patient had IgG anti-GM1, anti-GD1a and anti-GD1b. Modified from Uncini et al. ${ }^{19}$

demonstrated, in at least two nerves, an increase in distal CMAP amplitude $(>150 \%)$ at second study without increase $(>120 \%)$ of distal CMAP duration, or a reduced $(<0 \cdot 7)$ proximal CMAP/ distal CMAP amplitude ratio at first study which recovered without excessive CMAP temporal dispersion (proximal CMAP/ distal CMAP duration ratio >130\%) (figure 1B, C). In AMAN with RCF, DMLs may be slightly prolonged at first recording in some nerves (figure1B), usually $<130 \%$ ULN, although exceptions of up to $200 \%$ ULN are seen when the CMAP amplitude is $<10 \%$ of LLN. This latter 'demyelinating' feature, when detected in isolation, is acceptable within the electrodiagnostic criteria of AMAN. ${ }^{26}$ Slow conduction velocities can also be present but typically in nerve segments with conduction block. This slowing would typically reverse rapidly with resolution of conduction block (figure1C). ${ }^{19}$ In our group of patients, DMLs and distal CMAP amplitudes significantly improved at a second study performed at a mean of 34 days after onset. To summarise, AMAN with RCF is characterised by recovery within a few weeks of slightly prolonged DMLs, conduction slowing, reduced distal CMAP amplitudes and conduction block in intermediate nerve segments without excessive temporal dispersion of CMAPs. ${ }^{20}$

In the study from Cucuta, Colombia, 10 patients were described to have AMAN, although the authors reported prolonged DMLs and sural-sparing pattern which have typically been described in AIDP. ${ }^{10}$ In the French-Polynesian and Cucuta studies, individual electrophysiology data were not published. Moreover, the presentation of electrophysiology data in median values in the French-Polynesian studies may have obscured a variety of electrophysiological subtypes. Taking these factors into account, we would caution against a definitive interpretation of their neurophysiology findings as AMAN.

In the study from Colombia, electrophysiology data were provided for 46 patients. The authors report 36 patients with electrophysiological features of AIDP based on the Hadden and Ho criteria. ${ }^{26} 27$ In the absence of published electrophysiology reference ranges in their cohort, the key findings of demyelination in the majority of patients are likely to be represented by prolonged DMLs and in some nerves, there are also conduction block, slowed velocities and prolonged $\mathrm{F}$ waves. Sural-sparing pattern, defined as the presence of sural sensory nerve action potential in the absence of median sensory nerve action potential, ${ }^{28}$ was seen in 14 of 29 AIDP patients with sensory studies of these nerves. In a previous study, this pattern has been shown to be $100 \%$ specific in distinguishing AIDP from AMAN. ${ }^{28}$ In a single patient, a diagnosis of AMAN was made as there were reduced CMAP amplitudes with normal sensory studies. The remaining electrodiagnoses of their patients were equivocal in four patients, nerves were inexcitable in three patients and normal in two. As a second study was not reported in this series, the possibility of RCF could not be determined. 
As described earlier, the clinical characteristics of Zika-associated GBS displays a high frequency of facial palsy, ${ }^{3} 12$ a feature that is also more in keeping with AIDP than AMAN. In a Japanese-Italian GBS cohort, only $18 \%$ of antigangliosidepositive AMAN patients had facial palsy in comparison to $65 \%$ of antiganglioside-negative AIDP patients. ${ }^{29}$ In Zika-associated GBS, antiglycolipid antibody activity, mainly against asialo-GM1, was found at admission in $31 \%$ of patients, but the typical AMAN-associated antiganglioside antibodies were rarely present. $^{3}$ Currently, proof of pathogenic associations between Zika virus antigens and asialo-GM1 are lacking, raising doubts as to the significance of these antibodies in the pathogenesis of Zika-associated GBS.

We would conclude that the current evidence suggest that in most cases of Zika infection and GBS, the electrodiagnoses are consistent with a primary demyelinating neuropathy with predominant involvement of distal nerve segments typically represented by reduction in the mean terminal latency index. ${ }^{8}$ In AIDP, the distal nerve terminals, where the blood-nerve barrier is anatomically deficient, is preferentially affected, and prolonged distal latency and reduced terminal latency index are the most frequent and early nerve conduction abnormalities.

In order to gain a greater understanding of the pathogenesis of Zika-associated GBS through electrophysiology, serial studies and extensive data acquisition (including distal CMAP duration, median and ulnar sensory nerve conductions) are necessary. This should be followed by careful interpretation of individual patient electrophysiology data to allow for individual electrodiagnostic classification rather than combining results which is likely to introduce significant inaccuracies.

\section{GBS in association with other flavivirus}

Prior to the Zika virus outbreak, there have been case reports of GBS in association with other flavivirus infections, namely dengue, West Nile and Japanese encephalitis (table 1). ${ }^{30-42}$ Similar to Zika-associated GBS, the clinical characteristics are in keeping with classical GBS with symmetrical limb weakness, sensory disturbance and areflexia. Interestingly, these GBS patients also display facial palsy.

GBS in association with dengue infections has been widely reported and in 14 cases, limited electrophysiology information was also included. In the majority of cases, the electrodiagnosis was in keeping with AIDP with several authors describing prolonged distal latencies, slow conduction velocities and delayed $\mathrm{F}$ waves. $^{30-343637}$ In three cases where electrophysiology data were not provided, the authors concluded axonal subtypes of GBS (1 AMAN and 2 acute motor and sensory polyneuropathy). ${ }^{35} \quad{ }^{38}$ Our own unpublished observation of dengue-associated GBS would support AIDP. A Malay man aged 49 years presented with classical GBS following an acute dengue infection (confirmed by the presence of $\operatorname{IgM}$ against dengue virus). The first electrophysiology studies (day 9 of disease onset) demonstrated unrecordable sensory potentials. Motor studies revealed prolonged DML and distal CMAP durations, reduced conduction velocities (ranging $25-33 \mathrm{~m} / \mathrm{s}$ ) and delayed F waves. A second study at week 4 demonstrated further prolongation of DML and distal CMAP durations as well as further slowing of motor conduction velocities. By week 8, electrophysiology demonstrated recovery of CMAP amplitudes, but DMLs and CMAP durations remained prolonged and conduction velocities were slow, in keeping with the remyelination process.

In Japanese encephalitis and West Nile virus infections, acute flaccid paralysis is not an uncommon presentation. ${ }^{39-44}$ In the majority of cases, the paralysis is reminiscent of poliomyelitis with asymmetrical motor weakness, pure motor neuronopathy on electrophysiology and CSF pleiocytosis, in keeping with anterior horn cell damage by the virus. ${ }^{43} 44$ Rarely, patients have also been reported to have GBS with symmetrical weakness, depressed reflexes and CSF albumin-cytological dissociation. $^{39-42}$ Electrophysiology findings in these instances have suggested an AIDP subtype of GBS (table 1).

Based on the existing literature, the electrodiagnosis of GBS in patients with Zika and other flavivirus are supportive of AIDP, although at this stage, it would be overly simplistic to assume that all GBS cases associated with flavivirus are driven by the same pathophysiology.

\section{CONCLUSIONS}

It has been 8 months since the WHO declared a Public Health Emergency of International Concern, calling for expedited research to establish links between neurological disorders and Zika virus. ${ }^{45}$ As we face the Zika virus epidemic, further evidence in support of an epidemiological association between GBS and Zika virus will likely emerge. In order to address the current gaps in our knowledge of Zika-associated GBS, a systematic approach to the clinical and electrodiagnostic evaluation of cases is necessary. We would recommend when possible, accurate phenotyping and serial electrophysiology studies as both provide insights into the pathogenesis of GBS, especially when pathological samples are lacking.

Contributors AU and SK contributed to the conception of the manuscript. NS and $\mathrm{AU}$ contributed to the literature review, initial drafts of the manuscript, analyses of the electrophysiological data and preparing the tables. All authors contributed to the final editing of the manuscript.

Competing interests None declared.

Ethics approval Ethics Committee of Universities of Chieti, Malaya, Chiba.

Provenance and peer review Commissioned; externally peer reviewed.

\section{REFERENCES}

1 Shahrizaila N, Yuki N. Guillain-Barré syndrome animal model: the first proof of molecular mimicry in human autoimmune disorder. J Biomed Biotechnol 2011;2011:829129.

2 Gold CA, Josephson SA. Anticipating the challenges of Zika virus and the incidence of Guillain-Barré syndrome. JAMA Neurol 2016;73:905-6.

3 Cao-Lormeau VM, Blake A, Mons S, et al. Guillain-Barré syndrome outbreak associated with Zika virus infection in French Polynesia: a case-control study. Lancet 2016;387:1531-9.

4 Dos Santos T, Rodriguez A, Almiron M, et al. Zika virus and the Guillain-Barré syndrome? case series from seven countries. N Engl J Med Published Online First: 31 Aug 2016. doi:10.1056/NEJMc1609015

5 Oehler E, Watrin L, Larre $P$, et al. Zika virus infection complicated by Guillain-Barré syndrome-case report, French Polynesia, December 2013. Euro Surveill 2014;19: pii: 20720.

6 Fontes CA, Dos Santos AA, Marchiori E. Magnetic resonance imaging findings in Guillain-Barré syndrome caused by Zika virus infection. Neuroradiology 2016;58:837-8

7 Kassavetis P, Joseph JM, Francois R, et al. Zika virus-associated Guillain-Barré syndrome variant in Haiti. Neurology 2016;87:336-7.

8 Watrin L, Ghawché $F$, Larre $P$, et al. Guillain-Barré syndrome (42 cases) occurring during a Zika virus outbreak in French polynesia. Medicine (Baltimore) 2016;95: e3257.

9 Brasil $P$, Sequeira $P C$, Freitas $A D$, et al. Guillain-Barré syndrome associated with Zika virus infection. Lancet 2016;387:1482

10 Arias A, Torres-Tobar L, Hernández G, et al. Guillain-Barré syndrome in patients with a recent history of Zika in Cucuta, Colombia: a descriptive case series of 19 patients from December 2015 to March 2016. J Crit Care 2016;37:19-23.

11 Dirlikov E, Major CG, Mayshack $M$, et al. Guillain-Barré syndrome during ongoing Zika virus transmission-Puerto Rico, January 1-July 31, 2016. MMWR Morb Mortal Wkly Rep 2016;65:910-14.

12 Parra B, Lizarazo J, Jimenez-Arango JA, et al. Guillain-Barré syndrome associated with Zika virus infection in Colombia. N Engl J Med Published Online First: 5 Oct 2016. doi:10.1056/NEJMoa1605564 
13 Rozé B, Najioullah F, Fergé JL, et al. Zika virus detection in urine from patients with Guillain-Barré syndrome on Martinique, January 2016. Euro Surveill 2016;21.

14 Siu R, Bukhari W, Todd A, et al. Acute Zika infection with concurrent onset of Guillain-Barré syndrome. Neurology 2016;87:1623-4.

15 do Rosário MS, de Jesus PA, Vasilakis N, et al. Guillain-Barré syndrome after Zika virus infection in Brazil. Am J Trop Med Hyg Published Online First: 19 Sept 2016. doi:10.4269/ajtmh.16-0306

16 Sejvar JJ, Kohl KS, Gidudu J, et al. Guillain-Barré syndrome and Fisher syndrome: case definitions and guidelines for collection, analysis, and presentation of immunization safety data. Vaccine 2011;29:599-612.

17 Willison HJ, Jacobs BC, van Doorn PA. Guillain-Barré syndrome. Lancet 2016:388:717-27.

18 Wakerley BR, Uncini A, Yuki N, et al. Guillain-Barré and Miller Fisher syndromesnew diagnostic classification. Nat Rev Neurol 2014;10:537-44.

19 Uncini A, Manzoli C, Notturno F, et al. Pitfalls in electrodiagnosis of Guillain-Barré syndrome subtypes. J Neurol Neurosurg Psychiatr 2010;81:1157-63.

20 Uncini A, Kuwabara S. Electrodiagnostic criteria for Guillain-Barré syndrome: a critical revision and the need for an update. Clin Neurophysio/ 2012;123:1487-95.

21 Van den Bergh PY, Pieret F. Electrodiagnostic criteria for acute and chronic inflammatory demyelinating polyradiculoneuropathy. Muscle Nerve 2004;29:565-74.

22 Rajabally YA, Nicolas G. Value of distal compound muscle action potential duration prolongation in acute inflammatory demyelinating polyneuropathy: a European perspective. Muscle Nerve 2011;43:751-5.

23 Mitsuma S, Van den Bergh P, Rajabally YA, et al. Effects of low frequency filtering on distal compound muscle action potential duration for diagnosis of CIDP: a JapaneseEuropean multicenter prospective study. Clin Neurophysiol 2015;126:1805-10.

24 Kuwabara S, Yuki N, Koga M, et al. IgG anti-GM1 antibody is associated with reversible conduction failure and axonal degeneration in Guillain-Barré syndrome. Ann Neurol 1998;44:202-8.

25 Uncini A, Kuwabara S. Nodopathies of the peripheral nerve: an emerging concept. J Neurol Neurosurg Psychiatry 2015;86:1186-95.

26 Hadden RD, Cornblath DR, Hughes RA, et al. Electrophysiological classification of Guillain-Barré syndrome: clinical associations and outcome. Plasma Exchange/ Sandoglobulin Guillain-Barré Syndrome Trial Group. Ann Neurol 1998;44:780-8.

27 Ho TW, Mishu B, Li CY, et al. Guillain-Barré syndrome in northern China. Relationship to Campylobacter jejuni infection and anti-glycolipid antibodies. Brain 1995;118(Pt 3):597-605.

28 Hiew FL, Rajabally YA. Sural sparing in Guillain-Barré syndrome subtypes: a reappraisal with historical and recent definitions. Clin Neurophysiol 2016;127:1683-8.
29 Sekiguchi Y, Uncini A, Yuki N, et al. Antiganglioside antibodies are associated with axonal Guillain-Barré syndrome: a Japanese-Italian collaborative study. J Neurol Neurosurg Psychiatry 2012;83:23-8

30 Chew NK, Goh KJ, Omar S, et al. Guillain-Barré syndrome with antecedent dengue infection —a report of two cases. Neurol J Southeast Asia 1998;3:85.

31 Esack A, Teelucksingh S, Singh N. The Guillain-Barré syndrome following dengue fever. West Indian Med J 1999;48:36-7.

32 Santos NQ, Azoubel AC, Lopes AA, et al. Guillain-Barré syndrome in the course of dengue: case report. Arq Neuropsiquiatr 2004;62:144-6.

33 Kumar S, Prabhakar S. Guillain-Barré syndrome occurring in the course of dengue fever. Neurol India 2005;53:250-1.

34 Chen TY, Lee CT. Guillain-Barré syndrome following dengue fever. Ann Emerg Med 2007:50:94-5.

35 Verma R, Sharma P, Garg RK, et al. Neurological complications of dengue fever: experience from a tertiary center of north India. Ann Indian Acad Neurol $2011 ; 14: 272-8$

36 Ralapanawa DM, Kularatne SA, Jayalath WA. Guillain-Barré syndrome following dengue fever and literature review. BMC Res Notes 2015;8:729.

37 Simon O, Billot S, Guyon D, et al. Early Guillain-Barré Syndrome associated with acute dengue fever. J Clin Virol 2016;77:29-31.

38 Boo YL, Aris MAM, Chin PW, et al. Guillain-Barré syndrome complicating dengue fever: two case reports. Tzu Chi Med J Published Online First: 17 Nov 2015. doi:org/10.1016/j.tcmj.2015.09.007

39 Ravi V, Taly AB, Shankar SK, et al. Association of Japanese encephalitis virus infection with Guillain-Barré syndrome in endemic areas of south India. Acta Neurol Scand 1994;90:67-72.

40 Xiang JY, Zhang YH, Tan ZR, et al. Guillain-Barré syndrome associated with Japanese encephalitis virus infection in China. Viral Immunol 2014;27: 418-20.

41 Ahmed S, Libman R, Wesson K, et al. Guillain-Barré syndrome: an unusual presentation of West Nile virus infection. Neurology 2000;55:144-6.

42 Sejvar JJ, Bode AV, Marfin AA, et al. West Nile virus-associated flaccid paralysis. Emerg Infect Dis 2005;11:1021-7.

43 Sejvar JJ, Leis AA, Stokic DS, et al. Acute flaccid paralysis and West Nile virus infection. Emerg Infect Dis 2003;9:788-93.

44 Solomon T, Kneen R, Dung NM, et al. Poliomyelitis-like illness due to Japanese encephalitis virus. Lancet 1998;351:1094-7.

45 Broutet $\mathrm{N}$, Krauer $\mathrm{F}$, Riesen $\mathrm{M}$, et al. Zika virus as a cause of neurologic disorders. N Engl J Med 2016:374:1506-9. 